\title{
Mercantilização e Oligopolização no Ensino Superior Privado
}

\section{E्Eेuchãa}

Ronaldo Fabiano Gaspar

Tânia Costa Fernandes'

'Universidade Estadual de Londrina (UEL), Londrina/PR - Brasil

RESUMO - Mercantilização e Oligopolização no Ensino Superior Privado. $\mathrm{O}$ artigo analisa as mutações econômicas que o ensino superior privado tem passado nos últimos anos e, em particular, suas implicações sobre o perfil das instituições e a qualidade da educação. Nele, mostra-se como sua atual dinâmica expansiva tem favorecido a proliferação de capital estrangeiro e especulativo na composição acionária das holdings criadas para o controle de diversas instituições de ensino superior (IES), a oligopolização no setor, o incentivo dos recursos estatais e a crescente substituição da responsabilidade do estado pela dos próprios estudantes (e suas famílias) em relação ao custeio dos estudos nesse nível educacional. Por fim, expõe algumas implicações desse processo na qualidade da educação ofertada.

Palavras-chave: Educação. Ensino Superior Privado. Oligopolização. Qualidade Educacional.

ABSTRACT - Mercantilization and Oligopolization in the Private Higher Education. The article analyses the economic changes that the private higher education has passed in recent years and, in particular, its implications on the profile of the institutions and the quality of education. It shows how its current expansive dynamics has favored the proliferation of foreign and speculative capital in the ownership breakdown of holdings created for controlling of several higher education institutions (HEIs), the oligopolization in the sector, the incentive from state resources, and the increasing substitution of the state responsibility by the students themselves (and their families) in relation to the funding of studies in this educational level. Finally, some implications of this process on the quality of education are offered.

Keywords: Education. Private Higher Education. Oligopolization. Educational Quality.

Educação \& Realidade, Porto Alegre, v. 39, n. 3, p. 945-966, jul./set. 2014

Disponível em: <http://www.ufrgs.br/edu_realidade> 
Mercantilização e Oligopolização no Ensino Superior Privado

\title{
Introdução
}

No Brasil, a educação escolar universal, gratuita e de boa qualidade nunca foi, de fato, prioridade governamental. Embora essa constatação seja, muitas vezes, utilizada como mero elemento de retórica ou demagogia política, seu reconhecimento constitui um passo preliminar para o enfrentamento da difícil situação na qual ela se encontra. E, para ser efetivo, qualquer enfrentamento desse crônico problema-que, como se sabe, não podendo ser resolvido num sentido emancipatório na atual ordem societária, talvez possa ser amenizado - demanda, no mínimo, que a ação seja orientada pelo conhecimento aprofundado dessa esfera da realidade social. Sobre isso, não bastasse a constatação do grande atraso para a instauração e desenvolvimento de universidades e, com elas, de uma efetiva rede de ensino superior, é notório que muitos são os componentes desta estrutura socioeconômica e político cultural que atuaram (e atuam) para que, comparativamente, os índices nacionais de acesso e conclusão do ensino superior sejam baixos e, na média, a qualidade tão lastimável.

No seio das características estruturais de um país capitalista periférico ${ }^{1}$, a erosão de certos vigamentos econômicos e políticos do período da ditadura militar fomentou e/ou tem fomentado - sob a égide da burguesia financeira - processos de reestruturação produtiva, adequação neoliberal às demandas da globalização e reforma do regime político ${ }^{2}$; tudo isto com importantes implicações ideológico-culturais, em particular na reconfiguração da subjetividade dos trabalhadores em razão de novas demandas laborativas (técnicas e organizacionais) e seus desdobramentos mercadológicos (com fortíssimos apelos individualistas). Nesse contexto, o sistema educacional não poderia ter ficado imune a esses processos/acontecimentos e, muito menos, ter assumido configurações sumamente distintas das condicionantes socioeconômicas e políticas. Daí que, nessa transição das décadas de 80/90 do século passado,

\begin{abstract}
[...] a reforma da educação superior do país tornou-se progressivamente uma necessidade. Ela estava inscrita num processo que, como tendência geral, visava à reconstrução da hegemonia burguesa nas condições da particularidade brasileira. Processo este que dispensava a universidade autônoma, aberta às demandas das classes trabalhadoras, vinculada de alguma forma ao projeto de desenvolvimento capitalista nacional autônomo (Minto, 2011, p. 232).
\end{abstract}

Essas considerações são importantes porque nos permitem entender não somente que as mudanças em curso no sistema educacional são concernentes às estruturas e ao perfil de nosso desenvolvimento nacional - até o presente, amplamente desfavorável ao atendimento das demandas econômicas e políticas das massas populares -, mas, também, que a universalização do ensino superior (sobretudo público 
e gratuito) e a elevação de sua qualidade demandam muitíssimo mais do que vontade política, compromisso ético e projetos inovadores, termos que pululam nos discursos e documentos políticos, empresariais e de tantas ONGs. Mudanças dessa natureza exigem profunda transformação social em âmbito nacional e, até mesmo, mundial - que, por motivos diversos, não nos parece exequível a curto ou médio prazo. Decerto, não nos propomos a refletir aqui sobre as múltiplas determinações que se opõem a essa transformação no sistema educacional (o que, é claro, exigiria uma reflexão sobre transformações nos fundamentos de nossa formação socioeconômica e, por sua vez, demandaria conhecimentos e forças muitíssimo mais abrangentes do que os nossos). No entanto, sem negligenciar as conexões de nosso objeto de estudo com a totalidade social - e, mesmo, da totalidade do ensino superior -, o escopo de nossa reflexão é imensamente mais modesto: visamos identificar alguns aspectos do sentido e das características das mudanças em curso no ensino superior, mais especificamente no ensino superior privado. Para isso, com base no preceito marxiano de que se trata apreender a lógica da coisa não a coisa da lógica, não enquadramos a realidade num construto lógico e/ou metodológico abstrato, mas, por meio da análise de informações e dados oriundos de diversas fontes - IBGE, Inep, Pnad, Ipea e relatórios financeiros das empresas de educação - e do estabelecimento de algumas correlações estatísticas, buscamos apreender o movimento específico do objeto investigado.

Como na educação básica, o ensino superior no Brasil padece de muitos problemas, e, em que pesem suas particularidades, sua crise é igualmente multifacetada. De modo muito mais significativo, porém, do que em outras partes do sistema educacional, o conhecimento de suas condições específicas passa pela elucidação da dinâmica de expansão e crise de sua parcela privada - e, nela, das peculiaridades de suas relações capital/trabalho. Isso porque, de modo inverso à educação básica - em que as escolas públicas detêm $83,5 \%$ das matrículas (Inep, 2013) -, o setor privado, constituído cada vez mais por empresas que orientam suas práticas administrativas para a obtenção de lucro (exceções, aqui, apenas as declinantes instituições comunitárias e/ou filantrópicas que, a princípio, atuam sem fins lucrativos), detém $73 \%$ do total de alunos matriculados na graduação superior (Inep, 2012). E, também aqui, a quantidade possui implicações qualitativas. Tratando-se de simples ampliação numérica - dado que os problemas de qualidade são de ordem mais profunda e complexa -, os entraves mais imediatos à expansão do ensino superior são o gargalo do ensino médio - pois a taxa de escolarização deste define o quantum da população que tem potencial educacional formal para adentrar naquele - e as precárias condições econômicas que dificultam a ascensão escolar de parte da população que possui o referido potencial. Entraves, por sinal, passíveis de resolução a curto/médio prazo. 
Mercantilização e Oligopolização no Ensino Superior Privado

No primeiro caso, um dos desafios para a ampliação do acesso é aumentar a taxa de escolarização líquida da população no ensino médio regular, que se encontra em 79,4\% (2011), até mesmo porque as matrículas no ensino médio da Educação de Jovens e Adultos (EJA) vêm caindo nos últimos anos: de 1.608.559, em 2007, passaram a 1.345.864, em 2012 (Inep, 2013). Esta informação, inclusive, possui grande relevância para se entender melhor o ensino privado e sua dinâmica, pois, em 2011, 52,5\% dos matriculados em seus cursos de graduação tinham 25 anos ou mais. Nas públicas, para efeito de comparação, esse percentual é de 39,3\% (Inep, 2011). Outro desafio é aumentar substancialmente o número de concluintes. Para isso, dentre outras ações, trata-se de reduzir a taxa de abandono, que, apenas na última série, chegou a 10,3\% em 2010 (Inep, 2011). No ciclo de séries, "A estimativa é de que apenas $66,6 \%$ dos alunos que ingressam no ensino médio o concluam" (Ipea, 2009 , p. 21). No segundo, a questão é o atendimento da parcela de diplomados do ensino médio que, embora aspire a frequentar o ensino superior, não tem condições para isso porque as vagas nas públicas são muito limitadas (e, portanto, o filtro da concorrência atua severamente, sobretudo em relação aos indivíduos dos estratos mais pobres) e/ou não possui renda necessária para arcar com o custo das mensalidades das instituições privadas. Nesse caso, as problemáticas orientações governamentais dos últimos anos têm sido de viés privatizante, limitadas em quantidade de atendimentos e promotoras de uma educação de qualidade bastante questionável. Por fim, além destes, talvez ainda haja outro contingente de potenciais frequentadores do ensino superior que mereça atenção: aqueles que, embora disponham renda, não querem frequentá-lo ou não possuem (ou, nas circunstâncias atuais, talvez seja mais correto dizer: supõem não possuir) o repertório científico-cultural adequado para enfrentar as demandas intelectuais desse nível educacional $^{3}$.

Seja como for, o fato é que, motivado por uma relativa estabilidade econômica do país nas últimas duas décadas, aumento da renda dos estratos intermediários e pobres da população, barateamento das mensalidades das instituições privadas e, inclusive, incremento numérico de IES públicas e suas respectivas vagas ${ }^{4}$, o ensino superior vivenciou um inequívoco ciclo de expansão: o número de matrículas aumentou $299,9 \%$ entre 1995 e 2012, passando de 1.759 .703 para 7.037 .688 (tabela 1) - e isso apesar dos gargalos quantitativos e qualitativos nos níveis de ensino que o antecedem. Todavia, essa expansão ocorreu com nítido apoio de políticas públicas que privilegiaram o ensino superior privado ante o público. Para Silva Júnior (2005, p. 107),

A forma atual do capitalismo no Brasil produziu uma regulação social que procura a "nova institucionalidade", assentada na busca do consenso entre antagônicos por meio de políticas de negociação e de uma brutal ofensiva ideológica contra tudo o que seja aparentado com a so- 
berania popular, submetida à política econômica aceita desde o início dos anos 1990.

E, em consonância com essa avaliação das forças e ideias hegemônicas na política brasileira nas últimas décadas, Rodrigues enfatiza:

[...] o crescimento da iniciativa privada no campo educacional, que não vem acontecendo pela 'mão invisível' do mercado, é fruto de uma política relativamente clara dos governos democraticamente eleitos, em plena sintonia com as orientações dos organismos multilaterais, como o Banco Internacional de Reconstrução e Desenvolvimento (BIRD), a Organização das Nações Unidas para a Educação, a Ciência e a Cultura (Unesco) e, mais recentemente, da Organização Mundial do Comércio (OMC) (Rodrigues, 2007, p. 17).

Por quê? Ora, os motivos são bastante conhecidos: enquanto a expansão da rede pública demanda vultosos investimentos estatais diretos (seja federal, estadual ou municipal) para a construção de novas instituições e/ou expansão da rede existente - o que significa gastos em edificações, laboratórios, professores etc. -, a expansão da rede privada depende primordialmente da elevação da renda da população (fenômeno natural, pouco controlável) e de políticas públicas de incentivo financeiro - com custos muito menores - em modalidades variadas (Prouni, Escola da Família, Bolsa-alfabetização, dentre outras), as quais implicam em expansão do mercado e perspectivas ascendentes de lucro, estimulando os investimentos capitalistas no setor. Em muitos casos, ainda, pouco comprometem - em comparação com a expansão direta de vagas - os recursos estatais, pois resultam em longas dívidas para os estudantes, como o Fies, da CEF; o Educred, mantido por algumas IES; o Pravaler (do Itaú e do IFC, braço do Banco Mundial); além de financiamentos oferecidos por outros bancos privados.

No caso do Fies, o mais importante programa de crédito estudantil do país, os dados são tão esclarecedores que, a partir deles, fica evidente o entusiasmo das empresas educacionais com a adesão dos alunos ao longo endividamento junto à Caixa Econômica Federal. De fato, a expansão do Fies ocorre com pleno incentivo das empresas de educação, pois, ao contrário da mensalidade paga pelos próprios estudantes, com o financiamento não há inadimplência; por isso, praticamente todas as grandes empresas educacionais fazem do endividamento dos alunos uma política de marketing (e de meta) das empresas (inclusive, com suspeitas de práticas fraudulentas para captação de alunos, como é o caso notório da Uniesp - Correa, Takahashi, 2012, p. C3). Em razão disso, "De 2010 a 2012, o programa teve 603,5 mil contratos [...] Os contratos representam R\$29,1 bilhões desde 2010” (Saldaña, 2013, s/p.). Não é casual, portanto, que, em 1999, no bojo das mudanças da legislação de incentivo ao ensino superior privado, o governo tenha substituído o Creduc (Crédito Educativo) pelo Fies (Financiamento Estudantil), 
Mercantilização e Oligopolização no Ensino Superior Privado

tendo em vista que, devido à taxa de juros fixa, este é mais atrativo para os estudantes. Naquele, a taxa de juros era $6 \%$ ao ano + TR, o que tornava bastante incerta evolução dos débitos. Neste, além de fixa, a taxa de juros tem sido declinante nos últimos anos. Em 2012, ela caiu para $3,4 \%$ ao ano, aumentando ainda mais a já intensa busca pelo crédito. Enfim, em 2013, o governo não apenas ampliou os recursos disponíveis ao programa como tornou as restrições cadastrais impróprias para barrar o acesso do aluno ao crédito. E para dirimir qualquer dúvida sobre sua importância para as referidas empresas, bastam alguns trechos dos comunicados da Anhanguera Educacional e da Kroton ${ }^{5}$ aos seus (e aos potenciais) acionistas. Para a primeira, o Fies é fundamental porque amplia taxa de retenção dos alunos - isto é, diminui a possibilidade de evasão. Na graduação presencial,

[...] a penetração do Fies atingiu $36,3 \%$, sendo que esse índice supera $40 \%$ em todas as regiões do Brasil, exceto na região metropolitana de São Paulo, que conta com a maioria das unidades recém-adquiridas, onde o processo de oferta do Fies iniciou-se apenas em 2012. A Companhia espera que a crescente penetração do Fies impacte positivamente a retenção de alunos nos próximos meses e anos /.../ [Por isso,] continua animada com as perspectivas do Fies e espera contínua melhoria em suas métricas de retenção e contas a receber (Anhanguera..., 2013a, p. 3).

No trimestre anterior, em contraste com o otimismo recente, os administradores da empresa demonstraram certa preocupação com os desdobramentos negativos de uma perda financeira em razão de entraves financeiros e burocráticos, por parte da CEF, para que houvesse a liberação do Fies aos alunos:

\begin{abstract}
A receita líquida, particularmente no $4 \mathrm{~T} 12$, foi impactada pelo cancelamento de $\mathrm{R} \$ 13,4$ milhões em matrículas relativas a 5,1 mil alunos com restrições de crédito que tinham permissão para se matricular no início do segundo semestre, com a condição de que iriam contratar um empréstimo do Fies. No entanto, em agosto/12, os alunos foram impedidos de entrar no Fies devido ao término da vigência de uma liminar, que permitia que os alunos com restrições de crédito pudessem contratar empréstimo do Fies (Anhanguera..., 2013b, p. 4).
\end{abstract}

Na mensagem da administração da Kroton, o tom otimista a respeito do Fies salienta sua importância social e indica o caminho das pressões políticas: "Outro fator relevante para essa conquista [os resultados operacionais e financeiros da empresa em 2012] foi o contínuo esforço empreendido pela Kroton para o crescimento do Fies, programa essencial para o desenvolvimento da penetração do Ensino Superior no país" (Kroton, 2013a, p. 2). No $1^{\circ}$ semestre de 2013, o Fies constituiu o modo de custeamento dos estudos para $47,2 \%$ dos alunos ingressantes nos vestibulares da Kroton e, dentre os matriculados, “[...] atingiu 66,4

950 Educação \& Realidade, Porto Alegre, v. 39, n. 3, p. 945-966, jul./set. 2014 Disponível em: <http://www.ufrgs.br/edu_realidade> 
mil alunos, representando 44,4\% da base total de alunos de Graduação Presencial” (Kroton, 2013b, p. 1).

E mais, para coroar essa invejável e promissora meta educacional-financeira de fomentar o endividamento bancário de seus alunos,

\begin{abstract}
As ações da Anhanguera Educacional Participações SA, maior universidade privada do Brasil, e as de suas duas maiores concorrentes brasileiras estão superando seus pares globais. O setor está sendo impulsionado pelo aumento do crédito. Os empréstimos estudantis triplicaram após o governo cortar as taxas de juros e facilitar a quitação dos débitos. A Estácio Participações SA, terceira maior empresa do setor, registrou um retorno total de 91 por cento neste ano, o maior dentre as 32 faculdades privadas mundiais, mostram dados da Bloomberg. A Kroton Educacional SA, com sede em Belo Horizonte, ostenta um retorno total de 84 por cento, e a Anhanguera teve retorno de 64 por cento. Isso se compara a um retorno médio negativo de 30 por cento das ações de 15 faculdades dos Estados Unidos (Godoy; Moura, 2012, s/p.).
\end{abstract}

O estado, por sua vez, com essa política educacional vigorosa - e, como se vê, bastante coerente com as demandas e interesses populares: dai mais a quem já tem muito! -, contribui diretamente com a acumulação de capital por frações da classe burguesa (serviços e finanças).

Posto isso, a importância dessas condições - mercado favorável e políticas públicas - para o crescimento do ensino privado fica evidente quando se esmiúçam os números da evolução do setor e se verifica que a expansão acentuada pela qual passaram as instituições privadas de 1980 até 2012 não foi linear: em termos absolutos, saltaram de 885.054 para 5.140.312 alunos matriculados. Entre 1980 e 1995, período marcado por impasses econômicos, resistências populares às políticas neoliberais e crise fiscal, ocorreu uma redução percentual de 4,1\% nas matrículas dessas instituições - que passaram de $64,3 \%$ para $60,2 \%$ do total de alunos ${ }^{6}$; depois, no entanto, a situação se alterou bruscamente. Isso ocorreu porque, além de transformações socioeconômicas (cujas mais evidentes são a globalização e a transição do padrão técnico-organizacional taylorista-fordista para a acumulação flexível) e sociopolíticas (como o neoliberalismo), que produziram novas demandas de formação da força de trabalho (mais ligadas aos serviços do que à indústria ${ }^{7}$, aos comportamentos do que ao conhecimento técnico aprofundado e, no tocante à complexidade do trabalho, privilegiadoras da adaptação e internalização de tecnologias em detrimento da inovação) ${ }^{8}$, surtiram efeito as políticas de financiamento e, principalmente, as mudanças na legislação educacional que, a partir da LDB, visaram estabelecer um marco regulatório mais favorável ao investimento capitalista - e, assim, à ampliação das possibilidades/perspectivas de lucro - no ensino superior privado. Com isso, a participação percentual desse segmento no total de alunos matriculados no ensino superior elevou-se em $13 \%$, chegando a $73 \%^{9}$.

Educação \& Realidade, Porto Alegre, v. 39, n. 3, p. 945-966, jul./set. 2014.

Disponível em: <http://www.ufrgs.br/edu_realidade> 
Mercantilização e Oligopolização no Ensino Superior Privado

Tabela 1 - Distribuição das Matrículas por Categoria Administrativa - Brasil 1980-2012

\begin{tabular}{ccccccccc}
\hline & 1.980 & 1.985 & 1.990 & 1.995 & 2.000 & 2.005 & 2.010 & 2.012 \\
\hline Públicas & 492.232 & 556.680 & 578.625 & 700.540 & 887.026 & 1.246 .704 & 1.643 .298 & 1.897 .376 \\
Privadas & 885.054 & 810.929 & 961.455 & 1.059 .163 & 1.807 .219 & 3.321 .094 & 4.736 .001 & 5.140 .312 \\
Total & 1.377 .286 & 1.367 .609 & 1.540 .080 & 1.759 .703 & 2.694 .245 & 4.567 .798 & 6.379 .299 & 7.037 .688 \\
\hline \multicolumn{7}{c}{ Fonte: Inep. }
\end{tabular}

Nesse movimento, a ampliação da clientela vem sendo efetuada pela venda desses serviços a estratos da população que, na escala de rendimentos, ocupam posições cada vez mais baixas - portanto, população com renda inferior àquela que era usualmente compradora desses serviços. Inclusive, este é um fato que tem dado vazão a acaloradas discussões sobre as possíveis virtudes e/ou vicissitudes dessa expansão do ensino superior privado ${ }^{10}$.

Um fato curioso a respeito dessa intensa mercantilização do ensino superior é que, embora a inserção do país na onda neoliberalizante tenha sido relativamente tardia em comparação aos pioneiros - Inglaterra, Estados Unidos e alguns outros -, tanto a presença de instituições privadas quanto, dentre estas, das empresas de educação (instituições que visam lucro) na composição da totalidade do ensino superior é, por aqui, muito maior do que na imensa maioria dos países do mundo. No caso dos Estados Unidos, Tierney informa que,

[...] até os anos 1970, faculdades e universidades com fins lucrativos eram uma parte minúscula do universo do ensino superior. Em 1967, por exemplo, aproximadamente sete milhões de estudantes eram atendidos por instituições capacitadas a emitir diplomas deste nível nos Estados Unidos; e pouco mais de 22.000 destes estudantes, ou menos de um terço de $1 \%$, eram atendidos por aquelas. Em 2012, no entanto, elas tinham se tornado 12\% do mercado nos Estados Unidos (Tierney, 2012, p. 5).

Enquanto isso, no Brasil, as matrículas nas instituições com fins lucrativos representam mais de $75 \%$ dos estudantes do ensino superior privado - ou seja, mais da metade dos matriculados no ensino superior como um todo (Inep, 2009 - ver gráfico 1). 


\section{Gráfico 1 - Relação Entre Instituições com e sem fins Lucrativos no Ensino Superior Privado - Brasil 2001-2009*}

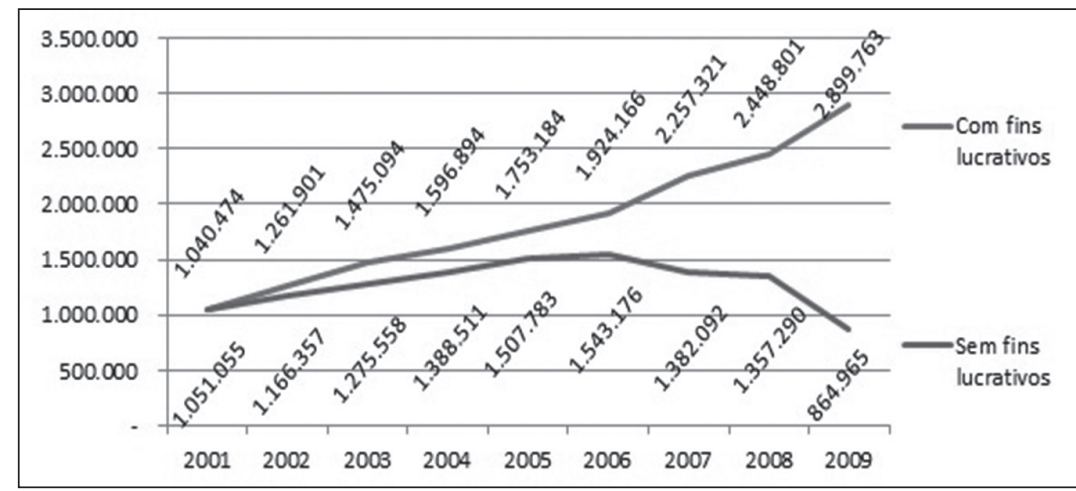

Fonte: Elaborado pelos autores a partir de dados das Sinopses do Ensino Superior publicadas pelo Inep.

* A partir de 2010, as Sinopses do Ensino Superior não mais distinguem as IES entre com e sem fins lucrativos.

Na América Latina, o Chile é o único país que possui maior presença de matrículas no ensino superior privado do que o Brasil - um dos espólios dos duros tempos de Pinochet. Não é sem motivos, portanto, que a mercantilização da educação superior no país tornou-se referência mundial. Num documento da Unesco, que dispunha de dados de 2005, o Brasil já era considerado um caso dramático no que diz respeito à presença de instituições de ensino superior com fins lucrativos. O setor privado com fins lucrativos

[...] está crescendo. Este parece ser o caso em todas as regiões em desenvolvimento. Um exemplo dramático é o Brasil, onde, em 2005, instituições legalizadas com fins lucrativos eram responsáveis por $19 \%$ do total de matrículas no ensino superior, não muito menor do que todo o setor público (Bjarnason, 2009, p. 20).

Lembrando ainda que, hoje, esse percentual ultrapassa os 50\%. Eis porque o país é destaque numa região que, por sua vez, é exemplo mundial em mercantilização do ensino superior. Como se lê no documento:

Em apenas quatro pequenos países as instituições privadas detêm menos de $20 \%$ [das matrículas no ensino superior], dois deles perto de 20\%; enquanto cinco países detêm mais de 50\% (Brasil, Chile, Costa Rica, El Salvador e Peru), com outros dois praticamente em $50 \%$ (Colômbia e República Dominicana) e outros dois beirando isso (Guatemala e Nicarágua). Em contraste, no Caribe anglófono o ensino superior privado é muito menor. A América Latina é o excelente exemplo regional da manutenção e ampliação de ações privadas, mesmo em meio à expansão pública sem precedentes (Bjarnason, 2009, p. 10). 
Mercantilização e Oligopolização no Ensino Superior Privado

Nessa onda amplamente propícia à acumulação de capital no setor privado, ocorreu não somente uma intensa expansão das empresas mais consolidadas e o surgimento de inúmeras outras similares, mas, especialmente a partir de meados da década passada, também a constituição e a consolidação de holdings gigantescas - em números de alunos e faturamento. Ou seja, uma tendência à oligopolização do setor. Entre 2001 e 2003, o número de IES privadas cresceu a taxas recordes de dois dígitos: 20,3\%, 19,4\% e 14,6\%; em compensação, em 2007, cresceu apenas $0,5 \%$ e, em 2008, houve declínio, $-0,8 \%$ (ver tabela 2). Observemos que o declínio da taxa de crescimento do número de instituições começou em 2004, não havendo, portanto, qualquer relação entre essa ocorrência e a crise mundial; nem, também, em relação à expansão das matrículas. Tanto que, no ano anterior ao estouro da bolha imobiliária americana, o número de instituições cresceu apenas $0,5 \%$, enquanto o de matrículas $7,78 \%$. No mesmo período, as atuais gigantes (Kroton, Anhanguera, Estácio) estavam se tornando empresas de capital aberto, iniciando suas fusões e compras e recebendo investimentos de fundos estrangeiros ${ }^{11}$. Diante desse quadro, não nos parece despropositado considerar a possibilidade de que o crescimento das empresas educacionais e a intensificação da concorrência - com sua necessária elevação dos patamares mínimos de investimento para o início de novos negócios na área - tenham sido fundamentais para frear o índice de crescimento do número de instituições e, em 2008, o tenha feito recuar em valores absolutos.

Tabela 2 - Distribuição das IES por Categorias Administrativas Brasil 1980-2012

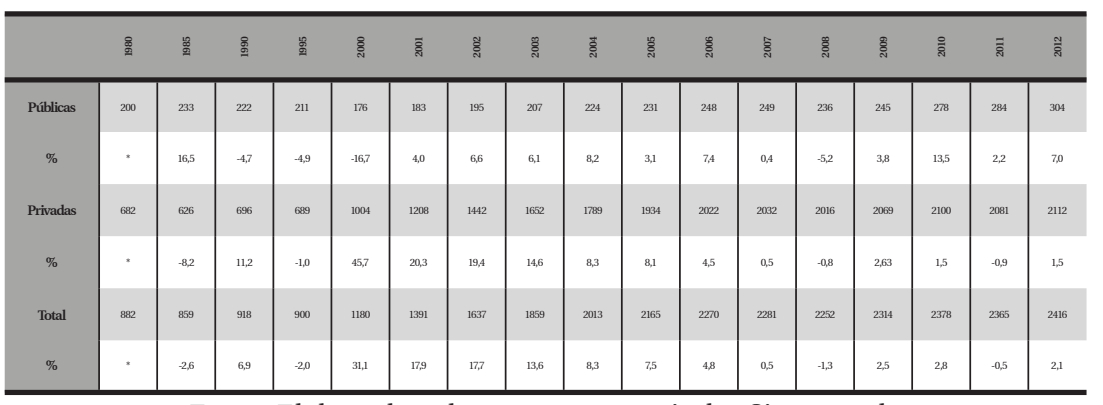

Fonte: Elaborada pelos autores a partir das Sinopses do

Ensino Superior publicadas pelo Inep.

De qualquer modo, o aumento dos investimentos e o espantoso crescimento do setor nos últimos quinze anos mostram-se na expansão/criação de instituições e, em razão dele, do número de vagas disponíveis nos processos seletivos ${ }^{12}$. De acordo com dados do INEP, em 1991 foi disponibilizado um total de 516.663 vagas para ingresso no ensino superior; em 2012, 4.653.814 - sendo, destas, 4.043 .096 no ensino priva$\mathrm{do}^{13}$. Como é usual em momentos de lucros e expectativas crescentes, essa ampliação fez com que, com o passar dos anos e a concretização de 
novos investimentos, o número de vagas ofertadas ultrapassasse largamente a demanda. Nas instituições privadas, até 1999, o percentual de vagas disponíveis acima do número de ingressantes girava em torno de $20 \%$. De 2000 em diante, esse percentual passou a crescer rapidamente, atingindo $111,3 \%$ em $2011^{14}$. Em 2012, por conta do grande crescimento do número de ingressantes ante o de vagas - 18,5\% e 3,1\%, respectivamente -, esse valor caiu para 83,2\% (Inep, 2013).

Para ampliar as dúvidas sobre o potencial dessa contínua expansão do mercado - e, com isso, as preocupações de todos os envolvidos nesse imbróglio educacional-comercial -, é importante mencionar que, nos últimos anos, tem ocorrido uma curiosa mudança na relação numérica entre concluintes do ensino médio e ingressantes no ensino superior, mudança que carrega em si substanciais implicações econômicas para o setor educacional privado. Para melhor compreensão do momento atual, uma observação da pesquisadora Helena Sampaio sobre a estabilidade (ou melhor, o baixo crescimento) de matrículas na primeira metade dos anos 1990 é elucidativo. Segundo ela, então, num estudo o ensino superior privado brasileiro - que, sob muitos aspectos, ainda é único -, "A estabilidade no número das matrículas de ensino superior, resultado da redução da demanda, deve-se, sobretudo, ao desempenho dos níveis educacionais que antecedem o ensino superior no país" (Sampaio, 2000, p. 89). Como o ensino médio é o provedor da demanda do ensino superior, a autora sustenta, não sem boa dose de razão, que o crescimento/estagnação deste deve acompanhar o crescimento/ estagnação daquele. Nos anos subsequentes à sua pesquisa, porém, devido aos motivos anteriormente elencados (estabilidade econômica, aumento da renda, barateamento das mensalidades), essa relação adquiriu uma configuração bastante diferente: o crescimento das matrículas no ensino superior foi substancialmente maior do que o crescimento dos concluintes do ensino médio ${ }^{15}$. E mais, dados recentes acerca dessa relação entre concluintes e ingressantes nos levam a afirmar que, se não é pelo incremento anual da quantidade de concluintes do ensino médio, a atual expansão do ensino superior só pode estar ocorrendo por meio do atendimento da demanda reprimida ou, então, pela captação, para uma segunda graduação, de indivíduos já formados. E, na verdade, pode-se afirmar que a dependência da demanda reprimida e da segunda graduação é muito maior do que os atuais inacreditáveis $34 \%$ de defasagem entre os respectivos grupos (concluintes e ingressantes), dado que nem todas as pessoas que concluem o ensino médio ingressam no ensino superior. Pior, como as taxas de escolarização do ensino médio pouco se alteraram nos últimos anos, a mudança na composição etária da população tem afetado negativamente a quantidade de concluintes do ensino médio, que, em números absolutos, atingiu seu pico em 2002 - 1.884.874 concluintes. Em 2011, foram 1.825.980 (Inep). Ou seja, quase como mercadorias no estoque de uma fábrica ou de uma loja, o problema para as empresas que atuam na área da educação é que vagas

Educação \& Realidade, Porto Alegre, v. 39, n. 3, p. 945-966, jul./set. 2014

Disponível em: <http://www.ufrgs.br/edu_realidade> 
Mercantilização e Oligopolização no Ensino Superior Privado

ociosas significam capital ocioso e transtornos à acumulação. Por isso, o ritmo desigual no crescimento de oferta e demanda instaurou, desde meados dos anos 2000, uma crise no setor de ensino superior - uma típica crise setorial ${ }^{16}$.

Note-se, entretanto, que essa captação fenomênica da dinâmica acumulação/crise do setor, embora contribua para uma compreensão de sua dinâmica total, também pode obliterar a situação específica de cada instituição e, com isso, os movimentos específicos das relações entre elas. Desse modo, como toda crise, esta não afeta a todas as empresas igualmente, mas favorece "as empresas capitalistas que possuem um grau de produtividade mais elevado", causando a ruína de muitas outras e, com isso, promovendo a centralização e a concentração de capitais. Por conseguinte, “[...] a dimensão média das empresas aumenta constantemente” (Mandel, 1989, pp. 223; 225)17. No estado de São Paulo, um rápido olhar pelo noticiário confirma essa tendência, pois é bastante grande o número de instituições de ensino superior que passaram (ou estão passando) por sérios problemas financeiros (Unicastelo, Unisantana, Unib, Unisa, PUC, Cásper Líbero), entraram em falência (São Luiz, Piratininga, São Marcos) ou foram incorporadas pelas concorrentes (Unicid, Uniabc, Faenac, Anchieta, Unibero, Uniban, Uniderp, dentre tantas outras) ${ }^{18}$. Uma das maiores implicações qualitativas desse processo expansionista é a larga ultrapassagem que, no número de alunos, as empresas de educação - especialmente as holdings educacionais - efetuaram em relação às universidades tradicionais, como PUCs, Mackenzie e outras fundações e instituições comunitárias, filantrópicas (ver gráfico 1). Por conta disso, a primeira década do século terminou com elas ocupando os postos mais elevados no ranking de alunos matriculados (ver quadro 1). Inequivocamente, esta situação traz consequências bastante danosas para diversos segmentos, como instituições financeiramente mais frágeis (fechadas ou incorporadas pelas maiores), estudantes (sujeitos a procedimentos educacionais pasteurizadores - apostilas, EADs etc.) e docentes (expostos ao rebaixamento salarial, precarização das condições de trabalho, desvalorização profissional).

Hoje, num universo de 2.112 instituições privadas que atuam no ensino superior, apenas sete controlam em torno de $35 \%$ do mercado $^{19}$. Com a fusão da Kroton com a Anhanguera, que espera aprovação do CADE, cerca de $16 \%$ serão controlados por uma única instituição - por sinal, a maior do mundo na área educacional ${ }^{20}$ - com enorme poder de barganha econômico e político ${ }^{21}$. E justamente a respeito desse assunto, a Estácio, em razão da ampla e crescente importância dos recursos do estado para a manutenção e expansão de seus negócios, mostra sem pudores o modus operandi dessa pressão política. Sendo assim, em seu último comunicado anual aos acionistas, lê-se:

Em 2012, [...] inauguramos o escritório de representação da Estácio em Brasília com o objetivo de dar apoio a to- 
das as IES do grupo na tramitação de seus processos junto aos órgãos reguladores, bem como acompanhar todos os assuntos educacionais nas esferas dos Poderes Executivo, Legislativo e Judiciário (Estácio, 2013, p. 63).

Quadro 1 - Maiores Instituições de Ensino Superior por Números de Alunos - Brasil 2012

\begin{tabular}{|cc|}
\hline & Número aproximado de alunos* \\
\hline Anhanguera & 429.000 \\
Kroton & 410.000 \\
Estácio & 271.000 \\
Unip & 238.000 \\
Laureate/FMU & 213.000 \\
Uninove & 127.000 \\
Uniesp & 106.000 \\
\hline Total & 1.794 .000 \\
\hline
\end{tabular}

Fonte: Elaborado pelos autores a partir de dados obtidos em balanços financeiros e informativos institucionais.

* Os números são aproximados porque, ao longo do ano, há flutuações nas matrículas (desistências, formaturas, ingressos etc.).

Com a brusca ascensão dos investimentos capitalistas no setor, as maiores empresas de educação se tornaram, então, sociedades anônimas e passaram a negociar as ações em bolsa, contando com forte participação de bancos e grupos de investimentos (nacionais e estrangeiros) em sua composição acionária ${ }^{22}$. "Entre os cinco maiores grupos educacionais do País, só a Unip não tem um grupo financeiro por trás de sua administração. A Anhanguera é comandada pelo Pátria; a Estácio, pela GP Investimentos; a Kroton, pela Advent e a Laureate tem participação do fundo americano KKR" (Oscar, 2012, s/p.). E, cada vez mais submetidas à lógica e ao ritmo de negócios do capital financeiro e especulativo, elas têm o lucro - de preferência, rápido e crescente - como único escopo de sua atuação ${ }^{23}$. Com efeito, metas de qualidade educacional, em geral bastante modestas, são perseguidas apenas como requisito - legal e de marketing - necessário para sua manutenção no mercado educacional24. "Para 2013", diz um comunicado da Anhanguera aos acionistas, “[...] o foco da companhia estará voltado novamente a desempenho operacional e geração de caixa, que possibilitará novamente o financiamento de sua expansão, combinado à redução da alavancagem" (Anhanguera, 2013b, p. 2). Essa busca voraz e insaciável pelo lucro - expressão subjetiva das determinações objetivas da valorização do valor - é um dos motivos da aversão demonstrada pelo Fórum Nacional da Livre-Iniciativa na Educação (2005) à participação docente e discente na gestão acadêmica e a uma suposta regulamentação excessiva do Ministério da Educação nesta área. Segundo Rodrigues (2006, p. 67-68), “[...] o 
Mercantilização e Oligopolização no Ensino Superior Privado

fórum execra qualquer tentativa de que se estabeleça alguma forma de gestão democrática, seja através da eleição de dirigentes, seja a partir do chamado (na última versão do projeto de reforma) conselho social de desenvolvimento”. E completa: “[...] os empresários do ensino não confiam no MEC como órgão avaliador do sistema educacional, posto que, dentre outros aspectos, o ministério simultaneamente regula, avalia e mantém instituições de educação superior".

Essa desconfiança dos empresários certamente é intensificada pelo fato nada casual de que nenhuma das instituições pertencentes aos grandes grupos financeiros ocupa uma posição de destaque em pesquisa, inovação, ensino ou qualquer outra dimensão positiva da educação superior ${ }^{25}$. De acordo com o IGC de $2011^{26}$, apenas 27 instituições alcançaram a nota 5 (máxima). Destas, 15 são públicas e 12 são privadas (respectivamente, $6,8 \%$ e $0,7 \%$ de seus respectivos grupos); sendo que, das últimas, nenhuma é universidade ou centro universitário, mas faculdades e institutos que atuam em nichos profissionais específicos, os quais cobram mensalidades muito altas e, com isso, são bastante seletivos quanto ao histórico escolar e à extração social de seus alunos ${ }^{27}$. Igualmente significativo é que $30,7 \%$ das instituições de ensino superior estão com notas 1 e 2 (34,5\% entre as privadas e 15,8\% entre as públicas) - portanto, abaixo da nota mínima aceitável, que é $3^{28}$. Nesse conjunto, há de se notar ainda que se a referência for o IGC contínuo, não o valor arredondado, somente 464 instituições - ou seja, 25,6\% - dentre as 1815 instituições (públicas e privadas) receberam nota acima de 2,5 $5^{29}$. Separando-se as dependências administrativas, esse percentual cai para $20,6 \%$ entre as instituições privadas e eleva-se para $60,2 \%$ entre as públicas. No caso das universidades, nas quais estão matriculados mais da metade dos alunos do ensino superior, 79,9\% das públicas obtiveram IGC contínuo acima de 2,5; entre as privadas, o índice foi de 46,7\%.

Outrossim, mais alguns importantes componentes organizacionais e acadêmicos que possibilitam que a educação ofertada seja de boa qualidade, como a formação docente e o regime de trabalho ao qual os professores estão submetidos, também nos informam algo sobre as instituições privadas. Pois bem, enquanto a proporção de doutores em relação ao total do corpo docente das IES públicas é de 50,9\%, nas privadas é de $16,5 \%$. No caso das universidades - excetuando, portanto, as outras IES (centros universitários e faculdades/ institutos isolados) -, os respectivos números são 56,0\% contra 24,0\% (Inep, 2011). No tocante ao regime de trabalho, a proporção das IES como um todo é a seguinte: públicas, $81,1 \%$ do corpo docente trabalham em regime integral; privadas, $25 \%$. Somente as universidades, temos respectivamente: $84,2 \%$ e 39,4\%. Sendo que, a respeito disso, ainda é sabido que nas instituições públicas o professor em regime integral geralmente ministra $8 \mathrm{~h} / \mathrm{a}$ por semestre, podendo dedicar o restante de suas 40 horas a atividades diversas, como orientação de alunos, pesquisa e extensão. Enquanto isso, nas IES privadas, o número de horas em sala de aula é normalmente muito 
maior, sendo bastante comum que as demais atividades que compõem sua carga horária não tenham qualquer relação com pesquisa, atividade primordialmente destinada às universidades, pois, ademais, os professores doutores precisam estar em diversos cursos para, neles, compor os percentuais mínimos exigidos nas avaliações do próprio MEC. Esses, portanto, são alguns aspectos do desalentador cenário composto pelo segmento privado do ensino superior brasileiro.

\section{Considerações Finais}

Em consonância com os objetivos iniciais, focamos nossa reflexão em algumas mutações quantitativas no ensino superior e, por sua vez, como estas têm provocado alterações qualitativas, sobretudo no setor privado. De acordo com nossa avaliação, o reordenamento desse nível educacional tem contribuído para, em conformidade com as exigências específicas dos tempos atuais, perenizar um sistema de ensino adequado às demandas socioeconômicas e político-culturais das classes dominantes de um país capitalista periférico, as quais, excetuando atividades bastante específicas, não necessitam de uma abrangente força de trabalho de profunda formação técnico-científica. Por isso, tenham ou não consciência disso seus executores, as atuais políticas públicas voltadas ao ensino superior têm correspondido aos anseios de uma classe dominante incapaz de admitir - quanto mais fomentar e/ ou sustentar - transformações sociais que atendam às demandas mais profundas das massas populares. Em outros termos, elas têm implicado em mudanças acessórias que, de fato, corroboram a essencial manutenção de um ordenamento social que reforça inúmeras mazelas econômicas (pobreza, desigualdade, dependência aos países centrais), políticas (fragilidade de instâncias, mecanismos institucionais e procedimentos democráticos) e culturais (elevado analfabetismo pleno e funcional, acesso precário às produções artísticas, filosóficas e científicas de elevada qualidade, tanto no tocante à fruição quanto à produção).

No tocante à configuração do ensino superior, essas mutações em curso têm acentuado uma de suas características mais evidentes - ser prioritariamente composto por IES privadas - e, no interior destas, invertido drasticamente a distribuição entre IES sem e com fins lucrativos, com ampla vantagem numérica das últimas. Com isso, em prejuízo da sólida formação acadêmica, o estado tem efetuado ações que tanto contribuem para o atendimento de demandas educacionais imediatas de certos estratos da força de trabalho quanto, com uma oneração relativamente baixa do tesouro - o que, inclusive, atende aos interesses do capital financeiro (superávit primário, pagamento das dívidas) -, fortalecem a fração burguesa relacionada às atividades de serviços. Nesse sentido, longe de corresponder a erros políticos que, oriundos do desconhecimento, incompetência ou pura má-fé, possam ser corrigidos pela simples ação político-administrativa, as referidas políticas públicas educacionais sustentam mutações concernentes às condicionantes

Educação \& Realidade, Porto Alegre, v. 39, n. 3, p. 945-966, jul./set. 2014

Disponível em: <http://www.ufrgs.br/edu_realidade> 
Mercantilização e Oligopolização no Ensino Superior Privado

sociopolíticas do país, as quais vêm ao encontro das demandas burguesas de recomposição dos modos de exercício de sua hegemonia interna ao mesmo tempo em que mantém a subalternidade nacional na nova quadra globalizante e neoliberal do capital. E é neste contexto que a formação acadêmica ganha contornos concretos, pois, do ponto de vista do capital, ela não é mensurada pela solidez humanística e técnico-científica dos estudantes, mas, no limite, pela régua da funcionalidade ao sistema.

Por fim, embora elucidativas sob diversos aspectos, as observações desenvolvidas aqui demonstram a necessidade de uma reflexão mais detida sobre as determinações subjacentes às mudanças no ensino superior, não apenas para esclarecer os fundamentos econômicos da crise e da concentração de capitais no ensino privado - ultrapassando, assim, o plano primordialmente fenomênico -, mas também para apreender seus desdobramentos laborais e educacionais. Portanto, uma reflexão que trate de um aspecto bastante negligenciado nas análises sobre a expansão do ensino superior privado: a relação entre o aumento da exploração do trabalho docente e a ampliação dos lucros das empresas, sobretudo num ambiente de intensa concorrência. Este, porém, é assunto a ser tratado num próximo artigo.

Recebido em 28 de maio de 2013 Aprovado em 21 de dezembro de 2013

\section{Notas}

1 Isto é, no caso brasileiro, um país marcado pela industrialização hipertardia (portanto, incompleta e dependente nos aspectos técnicos e financeiros dos países centrais), acentuada pobreza das massas populares e democracia perpassada por instituições e práticas autocráticas.

2 Como sustenta J. Chasin, no fim dos anos 1980 encerrou-se o longo ciclo de instauração/consolidação de nosso capitalismo industrial efetivado pela "via colonial" (ou, quiçá, de nossa "revolução burguesa" pelo alto) e, por conseguinte, das possibilidades de desenvolvimento capitalista autônomo - com maior completude de suas bases produtivas, elevação do padrão de vida material e cultural das massas populares e instauração de uma democracia burguesa. Para ele, "O sistema produtivo nacional, desde sempre, encarnou seus perfis e o teor de suas modernizações subordinado aos empuxos dos polos hegemônicos mundiais. Não é diverso o que se passa agora, diante da mais radical das revoluções tecnológicas, combinada ao quadro da globalização econômica. Todavia, dada a qualidade e a envergadura destas e o próprio grau de desenvolvimento material alcançado no país, as margens de manobra nos ajustes e seus efeitos possíveis também se diferenciam, ao mudar de natureza" (Chasin, 2000, p. 303).

3 Nesse caso, uma investigação sobre os motivos que fazem com que indivíduos formados no ensino médio não busquem frequentar o ensino superior, bem como sobre as principais causas da evasão neste nível de ensino, podem ser esclarecedoras. 


\section{Gaspar; Fernandes}

4 Na última década, com mais ênfase a partir do Programa de Apoio a Planos de Reestruturação e Expansão das Universidades Federais (Reuni), instituído pelo Decreto no 6.096 , de 24 de abril de 2007, essa expansão tem ocorrido sob as críticas dos mais diversos setores - acadêmicos, sindicais, sociais -, pois tem implicado na mercantilização das instituições públicas e na precarização do trabalho docente (ensino, pesquisa e extensão). Dentre muitos trabalhos sobre o tema, ver especialmente Lima (2007) e Sguissardi, Silva Júnior (2009).

5 Embora a fusão da Kroton e da Anhanguera tenha sido anunciada no primeiro semestre deste ano (2013), elas são aqui tratadas como empresas separadas porque, como o processo está em avaliação pelo Cade (Comissão Administrativa de Defesa Econômica), a integração de suas operações só poderá ocorrer efetivamente após parecer favorável deste órgão governamental.

6 Inclusive, em termos absolutos, declinou entre 1980 e 1985 (ver tabela 1).

7 Essas mudanças promoveram alterações na composição e na correlação de forças internas à própria classe burguesa. Para Boito Jr. (2005, p. 56), "[...] a mercadorização de direitos e de serviços como saúde, educação e previdência também atende, de modo variado, diferentes setores da burguesia - desenvolvem-se os negócios de uma fração burguesa que eu denomino nova burguesia de serviços, beneficiária direta do recuo do Estado na área dos serviços básicos, e reduzem-se, ao mesmo tempo, gastos sociais tradicionais, atendendo à pressão do grande capital". Recuo do estado que, como o caso do Fies exemplifica, não significa necessariamente afastamento das atividades, mas também novas modalidades de financiamento que favorecem o capital privado.

8 Uma interessante e elucidativa reflexão sobre o tema pode ser encontrada em Ramos (2006).

9 No estado de São Paulo, o mais rico da federação, esse processo, além de ter começado mais cedo, atingiu níveis ainda mais expressivos. Por motivos diversos, como escassez relativa de instituições públicas e renda mais elevada, a participação percentual das matrículas do ensino superior privado paulista chegou, em 2012, a 1.509.420 - isto é, 85,6\% do total de alunos matriculados. E, ademais, é necessário salientar que, no mesmo ano, 2,3\% do total de alunos encontravam-se matriculados em instituições municipais, as quais, em geral, cobram mensalidades (Inep, 2012).

10 Num comunicado da empresa Anhanguera Educacional que expõe aos seus investidores os resultados operacionais do $4^{\circ}$ trimestre de 2012, lê-se: "A maioria de seus alunos são jovens de média e média-baixa renda que trabalham durante o dia e estudam à noite, um segmento pouco atendido pelas instituições de ensino superior do Brasil" (Anhanguera, 2013a, p. 27). A exposição pode ser enaltecedora porque, como, por meio desse movimento econômico, há a incorporação dos estratos da população ao - antes inacessível-ensino superior, as discussões sobre a qualidade da educação ofertada ficam obliteradas pela ascensão educacional em si, constituindo uma das justificativas políticas e ideológicas ao baixo questionamento/enfrentamento em relação à qualidade duvidosa dos serviços educacionais prestados por essas empresas.

11 Para maiores informações, basta consultar notícias em jornais do período ou, de modo conciso e propagandístico, nas páginas dos sites das próprias empresas, mormente naquelas dedicadas aos investidores, onde há breves relatos das expansões, fusões e aquisições.

12 Este, por sua vez, é simultaneamente a manifestação mais visível da expansão e da crise - isto é, da dimensão econômico-financeira da crise. Nas palavras 
Mercantilização e Oligopolização no Ensino Superior Privado

do velho - mas atual - pensador: "A expansão súbita e intermitente da escala de produção é o pressuposto de sua contração súbita” (Marx, 1986(II), p. 201).

13 Para apoiar essa expansão, "Recentemente, o BNDES firmou com o Ministério da Educação (MEC) um acordo para viabilizar um novo programa de financiamento às IES públicas e privadas denominado Programa de Melhoria do Ensino das Instituições de Educação Superior. Para esse Programa, o BNDES dispõe de orçamento de $\mathrm{R} \$ 1$ bilhão, com vigência pelos próximos cinco anos [...] Os itens financiáveis pelo Programa incluem, além de investimentos fixos, a reestruturação financeira da IES, mediante apresentação de projeto de otimização operacional, com vistas a garantir a sustentabilidade financeira da instituição" (Sécca et al., 2009, p. 105).

14 Já em 2006, numa entrevista à Folha de São Paulo, Ryon Braga, presidente da mais importante consultoria da área educacional no país afirmou: "Foi uma verdadeira corrida ao ouro, todo mundo achava que podia ganhar dinheiro com faculdade [...] Muitas universidades que surgiram na época da fartura são incompetentes tanto na questão educacional quanto na gestão" (Ensino..., 2006, s/p.).

15 Em 1990/91, a relação entre concluintes do ensino médio e ingressantes no ensino superior era de 1,5 em favor dos concluintes; quase uma década depois - em 1999/2000 - essa relação aumentou para 2,0. Em 2005/06, essa relação, no entanto, foi invertida, com o número de ingressantes ultrapassando levemente o de concluintes; e, em 2009/10, de maneira mais acentuada, chegando a 21,4\%. E isso muito embora o ápice de alunos ingressantes no ensino superior como um todo tenha ocorrido em 2008, quando adentraram 2.336.899 novos estudantes. Nos anos seguintes, os números declinaram em 2009 (2.065.082) e 2010 (2.182.229), voltando a crescer em 2011 (2.346.695) e 2012 (2.747.089) (Inep).

16 "As dificuldades nas universidades são, segundo especialistas no setor, reflexo do forte crescimento na oferta de vagas desde a metade dos anos 90, quando o Ministério da Educação diminuiu as exigências para abertura de cursos. O problema é que a demanda não cresceu na mesma proporção” (Ano letivo..., 2012, s/p.).

17 “Com os 54 mil alunos da Uniban, a Anhanguera ultrapassa a marca de $400 \mathrm{mil}$ alunos [...] Os campus da Anhanguera, com a última aquisição [Uniban], passam a ter capacidade para 700 mil alunos. O grupo tem como objetivo alcançar, entre 2014 e 2015, a marca de 1 milhão de alunos, incluindo os atendidos por sistema de educação a distância. Isso elevaria a participação da empresa no mercado de educação superior brasileiro de $8 \%$ para $15 \%$ em alunos atendidos. A compra da Uniban faz da Anhanguera líder na Grande São Paulo, com 110 mil alunos" (Ninni, Cruz, 2012, s./p.).

18 “A GP Investimentos fechou a compra de $20 \%$ da Estácio Participações, grupo de educação de capital aberto com cerca de 200 mil alunos em 12 Estados e receita líquida de $\mathrm{R} \$ 640$ milhões em 2007. [...] O setor está em estado de agitação permanente, com 25 aquisições em 2007 e 13 neste ano. E o número de ativos de qualidade é limitado" (GP compra..., 2008, s./p.).E mais, "Após fechar a compra da Unicid, A Universidade Cruzeiro do Sul segue com apetite para aquisições. Segundo Fabio Figueiredo, diretor de desenvolvimento do Grupo Cruzeiro do Sul, há outras três conversas em andamento com outras universidades" (Após Unicid..., 2012, s/p.).

19 Para efeitos comparativos, vale lembrar que a maior e mais conceituada universidade pública do país, a USP, possui cerca de 58.000 alunos na graduação; ou seja, menos de $1 \%$ do total de alunos desse nível do ensino superior do país.

962 Educação \& Realidade, Porto Alegre, v. 39, n. 3, p. 945-966, jul./set. 2014 Disponível em: <http://www.ufrgs.br/edu_realidade> 


\section{Gaspar; Fernandes}

20 "Nos meios empresariais, o novo conglomerado já é considerado a maior instituição educacional do mundo, com um valor de mercado estimado em $\mathrm{R} \$ 12$ bilhões - valor que representa o dobro da segunda colocada, o grupo chinês New Oriental" (Concentração..., 2013, s./p.).

21 "Cinco das maiores companhias de educação que atuam no Brasil fundaram uma entidade para representar o setor e pedir a desoneração da folha de pagamento das instituições de ensino superior. A Associação Brasileira para o Desenvolvimento da Educação Superior (Abraes) foi fundada em janeiro deste ano e une Estácio, Kroton, Devry Brasil, Anhanguera e Laureate. A associação tem atuado junto ao Congresso Nacional pela aprovação de emenda incluída na MP 601/2012, que coloca as universidades particulares no Reintegra (Regime Especial de Reintegração de Valores Tributários para as Empresas Exportadoras)" (Sousa, 2013, s./p.).

22 Um exemplo recente: "Após um ano de negociações, o Grupo Cruzeiro do Sul Educacional vendeu $37 \%$ do seu capital para a gestora inglesa de fundos de private equity Actis por $\mathrm{R} \$ 180$ milhões" (Grupo Cruzeiro..., 2012, s/p.).

23 Na explicação de um consultor financeiro, os fundos de private equity "querem encontrar empresas com potencial e, assim, se tornarem seus sócios. Posteriormente, a fatia da empresa - ou a empresa como um todo - pode ser vendida (geralmente é)" (Pereira, 2012, s./p.).

24 Inclusive, uma curiosidade sobre o perfil da responsabilidade acadêmica dessas holdings pode ser observado num documento da Anhanguera aos investidores, que, dentre outros assuntos, analisa as despesas com marketing da empresa. Nele, pode-se ler o seguinte: "Despesas com marketing incluem: (i) publicidade veiculada em redes de televisão, outdoors, rádio, jornal, entre outros veículos; (ii) equipes internas de vendas e marketing; (iii) publicações de artigos de professores e alunos, (iv) pessoal de apoio ao departamento de marketing, entre outros" (Anhanguera, 2012, s/p. - grifos nossos). Ou seja, para essa empresa da educação, artigos não constituem uma questão de responsabilidade acadêmica - e, com isso, a ser tratada neste âmbito -, mas de marketing. Portanto, questão relacionada a demandas financeiras, não intelectuais. E mais, sob o acicate da concorrência, algumas instituições acabam se utilizando de procedimentos escusos para manter e/ou expandir sua parcela do mercado. Assim, em março de 2012, a Unip foi denunciada por fraudes que vinha cometendo na seleção de alunos para o ENADE. Por meio dessa fraude, atrasava as notas dos alunos considerados de baixo/médio desempenho e turbinava indevidamente as notas de seus cursos, as quais, posteriormente, se tornavam componentes importantes de suas campanhas publicitárias para a atração de novos alunos (cf. Pompeu; Lordelo; Silva, 2012).

25 Embora rankings sejam, sob diversos aspectos, questionáveis, muitas são as evidências demonstrando que não é sem motivos que, no recém-lançado Ranking Universitário do jornal Folha de São Paulo, as maiores instituições pertencentes às grandes holdings da educação - Unesa (Estácio), Unopar (Kroton) e Uniban (Anhanguera) - ocupem, respectivamente, os modestíssimos $89^{\circ}, 108^{\circ}, 137^{\circ}$ lugares entre as 188 universidades públicas e privadas do país.

26 Há um descompasso entre o número total de IES que consta nas Sinopses do Ensino Superior e o documento do IGC, ambos publicados pelo Inep. De qualquer modo, para efeito dos cálculos relativos à avaliação, utilizamos o documento do IGC, que pode ser encontrado em: <http://portal.inep.gov.br/ indice-geral-de-cursos $>$.

Educação \& Realidade, Porto Alegre, v. 39, n. 3, p. 945-966, jul./set. 2014.

Disponível em: <http://www.ufrgs.br/edu_realidade> 
Mercantilização e Oligopolização no Ensino Superior Privado

27 Em 2009, enquanto o valor médio da mensalidade de uma faculdade/universidade privada estava em torno de $\mathrm{R} \$ 367$, a FGV cobrava $\mathrm{R} \$ 2.400$; enquanto PUC e Mackenzie, por sua vez, cobravam cerca de R\$ 1.100 (Gallo, 2010, s./p.).

28 Neste cálculo, foram consideradas 1815 instituições, pois há 308 para as quais não foram atribuídos conceitos e, também, 11 que estão sob investigação do MEC.

29 Isto é, enquadrado nas notas 1, 2, 3, 4 e 5. Para melhor entendimento, importa esclarecer que a nota 3 é atribuída a qualquer instituição cujo IGC contínuo fica entre 1,95 e 2,94 .

\section{Referências}

ANHANGUERA Educacional reporta vestibular de 166 mil alunos, crescimento de $13,7 \%$ e crescimento de 35,9\% no lucro líquido. Valinhos: 2013a. Disponível em: <http://www.anhanguera.com/ri/>. Acesso em: 16 maio 2013.

ANHANGUERA Educacional atinge metas de EBITDA e geração de caixa após investimentos e reporta crescimento de $261 \%$ no lucro líquido em 2012 . Valinhos: 2013b. Disponível em: <http://www.anhanguera.com/ri/>. Acesso em: 10 abr. 2013

ANHANGUERA. Principais linhas de nosso resultado. Valinhos: 2012. Disponível em: <http://www.anhanguera.com/ri/>. Acesso em: 19 maio 2013.

ANO LETIVO começa com crise em faculdades. Folha.com, São Paulo, 2009. Disponível em: <http://wwwl.folha.uol.com.br/folha/educacao/ult305u495426. shtml>. Acesso em: 20 ago. 2012.

APÓS DOIS anos de GP, Estácio vai retomar processo de expansão. Valor Econômico, São Paulo: 2011. Disponível em: <http://www.valor.com.br/arquivo/866515/apos-dois-anos-de-gp-estacio-vai-retomar-processo-de-expansao>. Acesso em: 18 ago. 2012.

APÓS UNICID, Unicsul negocia compra de outras três universidades. Portal Ig, São Paulo, 2012. Disponível em: <http://colunistas.ig.com.br/poder-economico/2012/01/30/apos-unicid-unicsul-negocia-compra-de-outras-tres-universidades/>. Acesso em: 20 ago. 2012.

BJARNASON, Svava et al. A New Dynamic: Private Higher Education. France: UNESCO, 2009.

BOITO JR., Armando. A Burguesia no Governo Lula. Crítica Marxista, Campinas, Unicamp, n. 21, p. 52-76, 2005.

CHASIN, José. O Poder do Real. In: A Miséria Brasileira: 1964-1994: do golpe militar à crise social. Santo André: Ad hominem, 2000. P. 297-304.

CONCENTRAÇÃO no ensino privado. Estadão.com, São Paulo, 2013. Disponível em: <http://www.estadao.com.br/noticias/impresso,concentracao-do-ensino-privado-,1025_241,0.htm>. Acesso em: 02 maio 2013.

CORREA, Vanessa; TAKAHASHI, Fábio. Estudante financiado paga mais por curso. Folha de São Paulo, São Paulo, Caderno Cotidiano, p. C3, mar. 2012.

ENSINO superior tem metade das vagas ociosas. Folha de São Paulo, São Paulo: 2006. Disponível em: <http://wwwl.folha.uol.com.br/folha/educacao/ult305u18558.shtml>. Acesso em: 15 fev. 2013.

ESTÁCIO. Relatório Anual 2012. Rio de Janeiro: 2013. Disponível em: <http:// www.estacioparticipacoes.com.br/estacio2010/web/conteudo_pt.asp?idioma= $0 \&$ conta $=28 \&$ tipo $=41091>$. Acesso em: 15 maio 2013.

964 Educação \& Realidade, Porto Alegre, v. 39, n. 3, p. 945-966, jul./set. 2014 Disponível em: <http://www.ufrgs.br/edu_realidade> 
GALLO, Ricardo. Cai Valor de Mensalidade em Faculdade Particular. Folha de São Paulo, São Paulo, 2010. Disponível em: <http://www1.folha.uol.com.br/fsp/ cotidian/ff2106201001.htm>. Acesso em: 10 set. 2012.

GODOY, Denyse; MOURA, Fabíola. Anhanguera e Estácio superam globais com crédito em alta. Exame.com, São Paulo, 2012. Disponível em: <http://exame. abril.com.br/mercados/noticias/anhanguera-e-estacio-superam-globais-com-credito-em-alta>. Acesso em: 21 mar. 2013.

GRUPO CRUZEIRO do Sul recebe aporte e compra Unicid. Valor econômico, São Paulo, 2012. Disponível em: <http://www.valor.com.br/empresas/2496680/grupo-cruzeiro-do-sul-recebe-aporte-e-compra-unicid>. Acesso em: 22 ago. 2012.

INEP. Censo da Educação Escolar Básica 2012: resumo técnico. Brasília: Instituto Nacional de Estudos e Pesquisas Educacionais Anísio Teixeira, 2013.

INEP. Censo da Educação Superior 2011. Brasília: Instituto Nacional de Estudos e Pesquisas Educacionais Anísio Teixeira. Disponível em: <http://portal.inep. gov.br/superior-censosuperior-sinopse>. Acesso em: 10 mar. 2013.

KROTON. Resultados 4t12. Belo Horizonte: 2013a. Disponível em: <http:// ri.kroton.com.br/kroton2010/web/conteudo_pt.asp?idioma $=0 \&$ conta $=28 \&$ ti po $=3286>$. Acesso em: 20 abr. 2013 .

KROTON. Resultados 1t13. Belo Horizonte: 2013b. Disponível em: <http:// ri.kroton.com.br/kroton2010/web/conteudo_pt.asp?idioma $=0 \&$ conta $=28 \&$ ti po=3286 > . Acesso em: 18 maio 2013.

LIMA, Kátia. Contrarreforma na Educação Superior: de FHC a Lula. São Paulo: Xamã, 2007.

MANDEL, Ernest. O Capitalismo Tardio. São Paulo: Abril cultural, 1980.

MARX, Karl. O Capital. São Paulo: Nova cultural, 1986.

MINTO, Lalo Watanabe. A Educação da "Miséria”: particularidade capitalista e educação superior no Brasil. 2011. 322 fls. Tese (Doutorado em Educação) - Programa de História, Filosofia e Educação, Universidade Estadual de Campinas, Campinas, 2011.

NINNI, Karina; CRUZ, Renato. Anhanguera compra Uniban por R 510 milhões. Estadão.com, São Paulo, 2011. Disponível em: <http://www.estadao.com.br/ noticias/vidae, anhanguera-compra-uniban-por-r-510-milhoes,773921,0.htm>. Acesso em: 18 ago. 2012.

OSCAR, Naiana. Duas Concorrentes e um Professor em Comum. Estadão. com, São Paulo, 2012. Disponível em: <http://www.estadao.com.br/noticias/ impresso,duas-concorrentes-e-um-professor-em-comum,884773,0.htm>. Acesso em: 10 fev. 2013.

PEREIRA, Ricardo. O Brasil também tem private equity. Dinheirama, São Paulo, s/d. Disponível em: <http://dinheirama.com/blog/2008/07/23/o-brasil-tambem-tem-private-equity/>. Acesso em: 22 ago. 2012.

PNAD 2009 - Primeiras Análises: situação da educação brasileira - avanços e problemas. São Paulo: IPEA, 2010.

POMPEU, Sérgio; LORDELO, Carlos; SILVA, Cedê. Unip é Acusada de Turbinar Notas do Enade e MEC cobra Explicações. Estadão.com, São Paulo, 2012. Disponível em: <http://www.estadao.com.br/noticias/vidae,unip-e-acusada-de-turbinar-notas-do-enade-e-mec-cobra-explicacoes,843262,0. htm>. Acesso em: 25 ago. 2012.

RAMOS, Marise Nogueira. A Pedagogia das Competências: autonomia ou adaptação? 3. ed. São Paulo: Cortez, 2006.

Educação \& Realidade, Porto Alegre, v. 39, n. 3, p. 945-966, jul./set. 2014.

Disponível em: <http://www.ufrgs.br/edu_realidade> 
Mercantilização e Oligopolização no Ensino Superior Privado

RODRIGUES, José. Os Empresários e a Educação Superior. Campinas: Autores Associados, 2007.

SALDAÑA, Paulo. Nome Limpo deixa de ser Exigência para Financiar Faculdade. O Estado de São Paulo, São Paulo, 2013. Disponível em: <http://www. estadao.com.br/noticias/impresso,nome-limpo-deixa-de-ser-exigencia-para-financiar-faculdade-,994906,0.htm>. Acesso em: 20 mar. 2013.

SAMPAIO, Helena. Ensino Superior no Brasil: o setor privado. São Paulo: Hucitec, 2000.

SÉCCA, Rodrigo Ximenes; LEAL, Rodrigo Mendes; MENEZES, Natália Maria Lopes. O Apoio do BNDES a Instituições de Ensino Superior (IES): uma análise do primeiro Programa IES (1997-2007). BNDES Setorial, 31. Brasília, BNDES, 2009. SGUISSARDI, Valdemar; SILVA JÚNIOR, João dos Reis. Trabalho Intensificado nas Federais: pós-graduação e produtivismo acadêmico. São Paulo: Xamã Editora, 2009.

SILVA JR., João dos R. Pragmatismo e Populismo na Educação Superior: nos governos FHC e Lula. São Paulo: Xamã, 2005.

SOUSA, Dayanne. Donos de Escolas pedem Desoneração da Folha. Estadão. com, São Paulo, 2013. Disponível em: <http://www.estadao.com.br/noticias/ impresso,donos-de-escolas-pedem-desoneracao-da-folha-,1005445,0.htm>. Acesso em: 20 mar. 2013.

TIERNEY, William G. Regulating Private For-Profit Higher Education. International Higher Education, Boston, Boston College, n. 69, p. 5-7, outono 2012.

Ronaldo Fabiano Gaspar é doutor em Ciências Sociais pela PUC/SP. É professor de Ciência Política na Universidade Estadual de Londrina.

E-mail:rfsgaspar@uol.com.br

Tania Costa Fernandes é doutora em Educação pela PUC/SP. É professora de Políticas Públicas na Universidade Estadual de Londrina.

E-mail: fernandestc@uol.com.br 